Original Research Paper

\title{
Packaging of Herbal Medicine and its Connection to the Acceptance Rate of the Urban Population Viewed from a Biological, Agricultural, Economic, Business and Communication Perspective
}

\author{
${ }^{1}$ Muchtar Yunus and ${ }^{2}$ Susanne Dida \\ ${ }^{I}$ Faculty of Economics, Department of Educational Economics, \\ Universitas Negeri Makassar, South Sulawesi, Indonesia \\ ${ }^{2}$ Faculty of Communication Studies, Universitas Padjadjaran, Sumedang, West Java, Indonesia
}

Article history

Received: 08-07-2017

Revised: 03-10-2017

Accepted: 11-10-2017

Corresponding Author:

Susanne Dida

Faculty of Communication

Studies, Universitas

Padjadjaran, Sumedang, West

Java, Indonesia

Email: susanne2025@gmail.com

\begin{abstract}
This article discusses the packaging of traditional herbal medicine and its acceptance rate from a biological, agricultural, economic, business and communication perspective. With the many herbal medicines on market in Indonesia and across the global, many questions are emerging about the content, plant type, biological aspects, the economic value and the appropriate information necessary for public knowledge. All this requires a thorough discussion in this rapidly changing universe. Since, medicinal components are known to be of value but with many side effects, though advantages in most case out-weigh disadvantages [side effects]. For instance, the use of herbals can be found in "brotowali" which cures fever, rheumatism, and itches. Further, herbal medicines can also help to facilitate a cure of appendicitis, typhoid, blood vomit, diabetes, cancer, leprosy, whooping cough, stone bladder, syphilis, skin infection, blood feses, bloody and mucus excretion and many other such illnesses. Though in the previous, traditional herbal medicines were known for their being cheap, with limited chemical content and their easiness to find. Today, it is becoming the opposite. High concentration of chemical contents is now being discovered in many self-proclaimed traditional herbal medicines at times with high risks to life. The prices are no longer for all the masses but for a few who can afford. Modern industries have turned herbal products into expensive medicines especially for the middle and lower class urban population. From a communication perspective, though modern industries have taken-up the job of transforming the herbal products, society still has a negative perception that tradition herbs are but an extension of the paranormal/ or witch doctor. In this case, in the present paper we wish to explain from a multidiscipline perspective the information surrounding herbal medicine more so from the packaging angle and the acceptance rate of the urban population.
\end{abstract}

Keywords: Urban Population, Herbal Plants, Information Packaging, Economic and Business Value of Herbal Medicine, And Acceptance Rate Of The Urban Population

\section{Introduction}

Since time immemorial, human beings the worldover have depended on the local environment for survival. This is true to the medical sector too because before the establishment of modern health services and facility, traditional ways of healing and boasting the immune system were in place. These systems were affordable and available to everybody since most of the required law materials were got from the local environment. People used various plants to cure illnesses. The local law materials included leaves, 
roots, trunks, tree skins, flowers, and fruits which were then mixed to form medicinal herbs. The manner under which these herbal medicines are processed is economical though still rudimental. However, as time passes and in this modern era, herbs are still used but not in the same way as in the past.

Indonesia with its wide-spread tropical forests has various plants to be used as modern herbal medicine. This has led to research on the chemical content, agro-biological value, economic and business value of many of these medicinal herbs. In other words, experts are set to establish the purpose of the so called traditional herbal medicines on the entire human being. The most important point is that if the truth is obtained, information must circulate and such information should be well packaged ranging from the chemical content, side effect, biological and agricultural components of a product, the business and economic value to society and above all, the good news of the effect to cure numerous illnesses.

Though herbal medicines have a long history in the Indonesian society where they are commonly known as "Jamu" there is no serious research neither modern research conducted on this field. This has been confirmed by Supriyatna (2014) who notes that though there are many herbs found on the archipelago, only a few can meet the required standards that have been set by the formal bodies. This is affects the herbal industry in the country, affecting its investors holistically. Yet currently, it is known that herbal is spread all over throughout the archipelago.

In this case the community more so those interested the herbal sector need a driving force towards improving the content, chemical aspect, business/ economic aspects and communication, hence transforming the packaging. The current situation will change, where out of three hundred thousand herbal plants found in Indonesia, only thirty thousand of these herbs are said to be in use. Such a situation has been brought about by the lack of knowledge about the use of herbal plants. For instance, not many people understand and know the basic benefits of plants such as puspa, yet this herbal medicine has components which are said to cure cancers.

The University of Padjadjaran in collaboration with Japanese's research institutes, in one of their researches revealed that herbals such as puspa consist of content suitable for the cure of cancer and that there are several forms of such herbs on the archipelago not yet examined (Kompas, 2010). Most of these medicinal herbs are not exploited due to the public's lack of knowledge about their benefit.

Today, most people believe in modern medications than the local traditional ways treatment. This happens due to the lack of or inadquate information about herbs and the existing ways of treatment. According to integrated information theory, people can develop belief of something only when they have received adequate information from the right source. In this case, a provision of right information on herbal medicines could change people's habits and views, hence strengthening individual beliefs.

Research has shown that herbal products are of use to people's health; they are also cheap in price and are of low harmful chemical contents (Kompas, 2010). They are said to have few side effects if any compared to modern drugs, meaning herbal medicines are safe for consumption.

Indonesia being a culturally diverse archipelago stretching across $5100 \mathrm{~km}$ with a wide range of habitats (Whitten and Whitten, 1996; Mitra et al., 2007) is blessed with many kinds of plants which are of medicinal value (Mitra et al., 2007). The herbal medicinal among other are brotowali used as a cure for fever, rheumatism, and itches, bidara upas used as a cure for appendicitis, typhoid, blood vomit, diabetes, cancer, leprosy, whooping cough, stone bladder, syphilis, skin infection, blood feses, bloody and mucus excretion, and ciplukan that is also used as a cure for influenza, sore throat, bronchitis, goitre, scrotum swelling, abscess, ulcers, epilepsy, prostate swelling. There are several of such medicinal herbs found in Indonesia.

The herbal medicinal products are popular due to certain belief which including their being cheap, unknown and untested chemical contents and the fact that they are easy to obtain. Besides, being cheap, herbal medicinal products are of value to human health. Though their benefits have not yet received a warm welcome from urban society, they are much used in rural areas. The herbal industrializing has just started its investment in herbal medicinal production creating job opportunities but also expensive products which are becoming hard to acquire by the middle to low class of the urban society.

For the urban population, legality, brand name and clearance of a product is very important. This is in line with WHO's policy. WHO (1998) states that for medicinal herbal products a notification (listing) or registration procedure should be used and that the manufacturers, distributors or importers should provide information on their products, including providing the data on individual components (WHO, 1998).

Packaging goes hand in hand with Information. In this rapidly changing world, access has been made easy through Information and Communication Technologies which have become easier to access. This makes information about medicinal herbal products easy to find. Information about herbal products is important since it tells the public about the true nature of herbs. For instance, one will know that medicinal herbal products are safe with minimal side effects and not associated to any age group (Khan, 2016). Based on this background, in the present research, it is noted that the link between acceptance rate and factors such as Biological, Agricultural, Economic, Business and Communication Perspective is strong and fundamental, hence need for sustenance. 


\section{Materials and Methods}

For this research, we used a descriptive explanatory survey method. The methods of data collection comprised of question guides, observations, in-depth interviews and content analysis. De Vaus (2014) emphasizes that survey is not only collecting information where only questionnaires are used but a research method where other techniques are used. These techniques include structured and in-depth interviews, observation, and content analysis among others.

Sugiyono (2010) describes this kind of research as an approach used to analyze the people's status, condition, system of thinking and category of events or phenomenon which take place at certain interval of time.

The form of method predicts and depicts the information to be obtained. In other words, it can bring out the clear picture of a given situation, event and or phenomenon. Thus, there is confirmation due to the repeated nature and consistence of data. On this point, Sugiyono (2010) further notes that the repetition in quantitative is done to have a consistency in the research data, hence its reliability.

We therefore, employed a survey method to obtain data from ongoing events in the effort to search for information about institutions, social, economic, or politic (Nazir, 2011) nature regard herbal medicines. Just like, it is pointed out by De Vaus (2014; Sugiyono, 2010; Nazir, 2011) in the explanations above this research aimed to discover how substantial the packaging of medicinal plants and herbs could influence its widespread use among the urban dwellers.

We studied information about medicinal plants and herbs, their prices, the business aspect, chemical content as the main variables of the study. This appeared at the same as a correctional study, which Rakhmat (1995) describes as a study with measurable links between various aspects, predictable aspects, and can pave way for experimental studies.

\section{Findings and Discussions}

\section{Information about Herbal Plants}

Regarding a study conducted on a sample of 350 respondents in four cities of Indonesia, Makassar, Bandung, Bogor and Garut, it has been established that the respondents age lay in the age brackets of 15-25 Years, making up $31.43 \%$, while $26-35$ Years were $30 \%$, those in the age bracket of 36-45 Year were $17.43 \%$, and those who lay in the age bracket of 46-55 Years made up 14.86\%, and lastly, those above 55 Years were only $6.29 \%$.

According to WHO, it is very important to have the necessary information about required and relevant data about the medicinal plants and herbs. This is true more so regarding the directions from the ministry of health, which requires that details of dosages are made clear to the public.

In the findings, it has been revealed that television is a favorable media for the spreading of information about medicinal plants and herbs. This read from and observed from the responses obtained from the informants regarding the commonly used media. It was found that $42 \%$ of the population studies considered media an appropriate means for information delivery. While of preferred internet were $31.71 \%$, printed media such as magazines newspapers, leaflets together with other media consisted of $26.28 \%$.

It has been established Television turned out popular because it is distinct when it comes to information delivering. It provides audiovisual material with extensive reach. However, television as a media for information has weaknesses, for instance the inability to record information to be viewed on other occasions.

The information disseminated about medicinal plants and herbs is real but its sustainability depends on the costs and business aspect of the modern information and communication technologies. Because TV programs depend on program packaging, informants, message bundling, time slot, and duration, which require more funds.

According to the present study, there are hopes that if true information is spread about medicinal plants and herbs from trusted informants and such other, sources in the field of medicinal plants and herbs people could have a live interaction with these sources and ask more questions about the benefit of herbal plants.

Findings also raised a question concerning message and information that should be prepared in dissemination about herbal plants. Respondents state that message should be delivered briefly without reducing any information needed, easy to understand by using popular scientific words or language in daily life.

The Fig. 1 above describes a communication process of information about herbal plants adopted from Berlo (1960) communication model. In the regard of this research, the model explains elements of communication process of information about herbal plants. This model explains that a credible source of information about herbal plants comes from Health Ministries, academics, and herbal experts. While from message aspect reveals that people's expectation about the message on herbal plants should be brief, credible, using popular scientific words which are complete. From the model we also learn that the preferred channel of information for urban society is basically television.

\section{Level of Acceptance of Herbal Plants}

Herbal plants as a heritage from ancestors are living and spreading throughout Indonesia, thanks to the tropical weather, which helps the growth and makes it easily retrieved by Indonesian people. The high benefit value and non-chemical substance factors made herbal plants a prima donna of alternative medicine for the population. Conversely herbal plants have already become a massive industry, which in turn made it difficult to obtain by people who need it. 

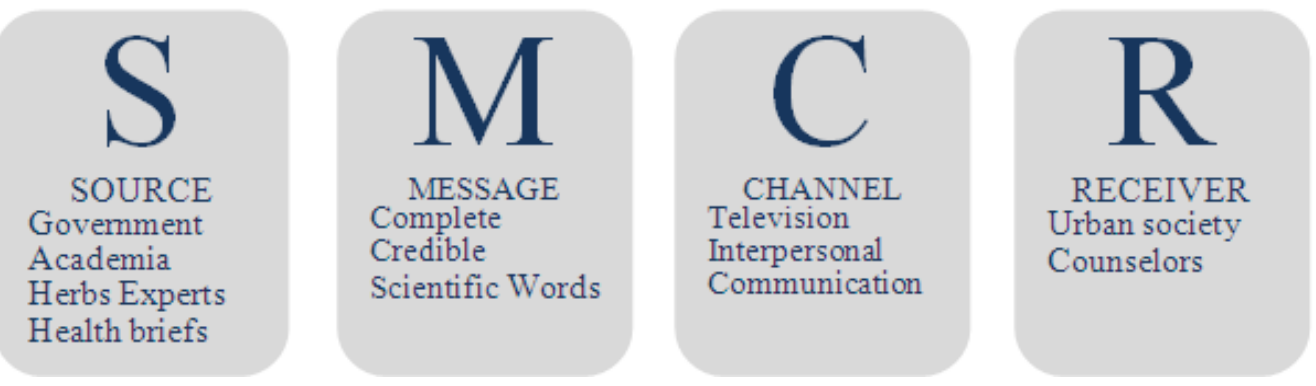

Fig. 1. Herbal Dissemination Model: A Modification of David K. Berlo's 1960 Communication Model

Table 1. Urban society perception about herbal plants

\begin{tabular}{llr}
\hline Perception & F & $\%$ \\
\hline Bad & 5 & 1.43 \\
Adequate & 164 & 46.86 \\
Good & 181 & 51.71 \\
Result & 350 & 100.00 \\
\hline
\end{tabular}

Table 2. People's interest on herbal plants

\begin{tabular}{llr}
\hline Interest & $\mathrm{F}$ & \multicolumn{1}{c}{$\%$} \\
\hline Low & 19 & 5.43 \\
Medium & 44 & 12.57 \\
High & 287 & 82.00 \\
Result & 350 & 100.00 \\
\hline
\end{tabular}

Table 3. Urban society belief towards herbal plants

\begin{tabular}{llr}
\hline Belief & $\mathrm{F}$ & \multicolumn{1}{c}{$\%$} \\
\hline Low & 3 & 0.86 \\
Medium & 53 & 15.14 \\
High & 294 & 84.00 \\
Result & 350 & 100.00 \\
\hline
\end{tabular}

Table 4. Urban society attitude towards herbal plants

\begin{tabular}{llr}
\hline Attitude & F & \multicolumn{1}{c}{$\%$} \\
\hline Bad & 4 & 1.14 \\
Sufficient & 117 & 33.43 \\
Good & 229 & 65.43 \\
Result & 350 & 100.00 \\
\hline
\end{tabular}

In addressing to this problem, government needs to have a policy to create herbal plants as alternative solution for health development project in Indonesia. From the data gathered in this research, level of acceptance of herbal plants is still high which can be seen Table 1 .

The Table 1 explains the urban society perception on herbal plants. Data show that $51.71 \%$ has a good perception on herbal plants while $46.86 \%$ has an adequate perception about it, and $1.43 \%$ considers it as bad. A good perception about herbal plants is triggered by the amount of information received by society about herbal plants. In disseminating information, herbal experts always use testimonial statements from cured patient using herbal treatment. The testimony featuring model from cured patients that being treated by herbal medicine, gives a deep impression for people so they consider herbal medicine as a method to treat illnesses. Method of dissemination of information on the use of herbal plants by using models encourages people to use herbal treatment, as can be seen Table 2.

Table 2 explains about categorization of respondent's appraisal about urban society interest on herbal plants. Data from the table shows that most of the respondents has a high interest on herbal plants with $82 \%$ and medium interest with $12.57 \%$ while the low interest with $5.43 \%$. Respondents' interest to use herbal plants proven by the high level of information search about the benefit of herbal plants, because of this level of interest, local and national media (especially television) developed many talk show programs which provide information about the benefit of herbal plants. Other than television, new media (internet) also provides information about herbal plants and on top of that become an online market for it. Those things confirm that society has a high belief for herbal plants which can be seen in the Table 3 .

The Table 3 explains belief category of urban society towards herbal plants. Data show that almost all urban society has a high belief towards herbal plants with $84 \%$, a medium belief with $15.14 \%$ and low belief with $0.86 \%$. Level of belief in society towards herbal plants is a result from a strong faith on herbal plants as a heritage from ancestors, meaning that herbal plants have been used since a very long time as a traditional medicine. The belief towards herbal plants is higher because of the cheap price and without any chemical content. Other than that, the other reason is the belief that herbal plants are as competitive as doctor prescribed medicine.

Table 4 shows that attitude of urban society towards herbal plants. Data show that most of urban society has a good attitude towards herbal plants with $65.43 \%$, sufficient attitude with $33.43 \%$ while people with bad attitude towards herbal plants consist of $1.14 \%$ out of population. The attitude of urban society towards herbal plants revealed by the willingness to provide information they received to other people. Society also inclined to have herbal plants planted on their yard with the intention to use those plants later. Other findings in this research are that people happily suggest their relatives to use herbal plants as alternative medicine. 


\section{Conclusion}

Based on the above description in the paper, we conclude that the level of acceptance for people towards medicinal plants and herbs is still high with the reason being cheap and has minimal chemical contents, though the chemical issue is also still under debate. The larger society believes that medicinal plants are a heritage from their ancestors, which needs to be preserved and maintained as a cure for the diseases.

\section{Acknowledgement}

We take the opportunity to thank all respondents and all those who helped in the process of writing this paper for their endless support.

\section{Author's Contributions}

All authors have been of positive contribution to this paper.

\section{Ethics}

Ethical issues have been followed in writing this manuscript.

\section{References}

Berlo, K.D., 1960. Berlo's SMCR Model of Communication.

De Vaus, D., 2014. Surveys in Social Research. 6th Edn., Routledge and Francis Group, London, pp: 382.

Khan, AM., 2016. Introduction and importance of medicinal plants and herbs. National Institute of Health and Family Welfare, India.

Kompas, B., 2010. Penelitian herbal belum mendalam. Kompas Cyber Media. Mitra, R., B. Mitchell, C. Gray, J. Orbell and T. Coulepis et al., 2007. Medicinal plants of Indonesia.

Nazir, 2011. Metode penelitian. Bogor: Ghalia Indonesia.

Rakhmat, J., 1995. Metode penelitian komunikasi. PT Remaja Rosda Karya, Bandung.

Sugiyono, 2010. Metode Penelitian Kuantitatif Kualitatif Dan R\&D. 1st Alfabeta, Bandung, ISBN-10: 9798433640, pp: 380 .

Supriyatna, A., 2014. Jamu banyak tapi masih sedikit yang Jadi herbal. Padjadjaran University, Indonesia.

Whitten, T. and J. Whitten, 1996. Indonesian Heritage: Plants. 1st Edn., Archipelago Press, Singapore.

WHO, 1998. Guidelines for the Appropriate use of Herbal Medicines. Essential Medicines and Health Products Information Portal a World Health Organization resource, pp: 88 . 